\title{
Bioethics and Culture:
}

\section{Understanding the Contemporary Crisis in Bioethics}

\author{
David Solomon
}

摘要

生命倫理學與文化的關係是晚近生命倫理學討論的熟點話 題。圍繞着布什生命倫理委員會 (President's Council on Bioethics or Bush Bioethics Council) 的種種風波和爭議, 使生命倫理學中的 文化權威問題尤為突顯。本文將審查布什生命倫理委員會的性 質, 並從新的視角解釋為什麼圍繞該委員會的爭論會陷入如此激 烈、不可調和的分裂中。我的新解釋是這些分裂與其説是生命倫 理學政治化的結果, 㸘説是文化深層分歧在生命倫理學和道德 哲學領域中的表達。

【關鍵字】 進步生命倫理學 生命倫理學帝國主義 布什生命倫理學委員會 自主 權威 道德中性 原則主義

David Solomon, 美國聖母大學哲學系教授, 美國。

《中外醫學哲學》XII:2 (2014 年) : 頁 87-117。

(C) Copyright 2014 by Global Scholarly Publications. 


\section{Introduction}

Much attention has been paid to the relation of bioethics and culture in recent years among those who primarily work in bioethics and also among those whose primary concerns are with matters of culture. ${ }^{1}$ Why? There are a number of reasons for this widespread interest, and in what follows I hope to explore the variety of these reasons and to suggest some ways of assessing the present state of this discussion. Among the conclusions of my discussion will be that the interplay between purely philosophical considerations bearing on contemporary discussions in bioethics and more general cultural considerations has been of the first importance in shaping recent developments in the emerging academic discipline of bioethics. One cannot ignore developments in academic moral philosophy if one hopes to understand why relations between bioethics and culture have been at the center of so many recent discussions. Also, I will suggest (but hardly establish) that the current unrest in bioethics centered on matters of its relation to culture grows ultimately out of deep cultural divisions and will not be easily resolved by mere adjustments in the methodology of bioethics or by "repackaging" bioethics.

My strategy in this paper will be first to distinguish two quite different sets of issues in the broad area of bioethics and culture and then discuss in some detail the second of these sets of issues. After exploring the second set of issues in a preliminary way I will relate them to some recent episodes in bioethics, in particular the vicious disagreements and lack of civility involved in the reaction of some establishment bioethicists to the deliberations of the Bush Bioethics Council. ${ }^{2}$ The depth of the disagreement and rancor in this case has led some to speak of a crisis in the field and of a need for some new methodological orientation for bioethics. Turning to a discussion of some general features of the history of bioethics since its creation half a century ago, I will suggest that these recent disturbances are rooted in features of bioethics present from its beginning. There has never been, as some suppose, a golden age when agreement was easy and mainstream bioethicists spoke with a single voice that

(1) The evidence for this is too ubiquitous to require evidence in this place. A simple search on the topic, "bioethics and culture," in any of the databases associated with bioethics will deliver an enormous number of books, articles, lectures, and conference programs that touch on these matters.

(2) The official name of this Council is the President's Council on Bioethics (PCBE), but I will refer to it in this paper, as many have been accustomed to do, as the Bush Bioethics Council. It was created by President George W. Bush in 2001, succeeding the National Bioethics Advisory Commission (NBAC) which was created by President Clinton in 1996 and expired in 2001. An excellent study of the Bush Council is found in Briggle 2014. 
commanded universal — or even near universal—assent. I will finally turn very briefly at the end of the paper to two important recent developments in the effort to reorient bioethics - the movement on the part of a number of establishment bioethicists to develop what they call Progressive Bioethics ${ }^{3}$ and the sociologist John Evans's recent proposal to draw on sociological insights to address the crisis in bioethics. I will argue that neither of these reforming proposals is adequate to resolve the difficulties in bioethics that elicited them.

\section{Consumer's Questions}

Many of the most important issues bearing on matters of bioethics and culture have been related to the attempt to globalize bioethics in recent decades and the cultural obstacles that this attempt has encountered. ${ }^{4}$ These obstacles have been especially noticeable when bioethics has attempted to broaden its reach beyond North Atlantic culture-where it was founded and came to cultural prominence - to East Asian and South Asian contexts. There have been particularly significant conflicts between the modern liberal, individualistic commitments of the bioethics spawned in Europe and North America in the last half-century and the more family related and tradition bound commitments of these Asian cultures. ${ }^{5}$ Although the literature on the conflicts between Anglo-European bioethics and the traditions and practices in diverse African communities is not as extensive, at this time, as that concerning Asian contexts, it is significant and growing. The sometimes hesitant and confusing responses of Western bioethicists to issues of female genital mutilation illustrate the difficult issues that arise in this area. ${ }^{6}$ The hesitancy in bioethical comment on these matters is one reflection of the great distance culturally from the seminar discussions of bioethics in an academic bioethics center at an elite

(3) The standard introduction to Progressive Bioethics is Moreno 2010, while Evans' views are found most fully set out in his book, The History and Future of Bioethics (2012).

(4) For an interesting and informative recent set of essays on the ambitions and difficulties of bioethical globalization one can hardly do better than Engelhardt 2006.

(5) These conflicts are particularly evident in the work of such philosophers as Ruiping Fan whose cultural outlook on contemporary biomedicine is deeply shaped by his own deep cultural embeddedness in traditional Confucianism, but who is also trained, not only in modern medicine, but also in the techniques of contemporary western bioethics. He has explored in a particularly illuminating way the problems of bringing the normative fruit of western bioethics to bear on contemporary debates about biomedicine as they come up in East Asian contexts. His article, "Confucian Reflective Equilibrium: Why Principlism is Misleading for Chinese Bioethical Decision-Making" (Fan 2012), is a particularly good example of his work. Fan, however, is just one exemplary representative of a number of Asian philosophers who have explored these issues.

(6) See, for example, the Report by the Public Policy Advisory Network on Female Genital Surgeries in Africa (2012). 
American university and the coming-of-age practices for adolescent females in an African village shaped by traditional African tribalism.

Even, however, when we remain within broadly North Atlantic cultural settings, we encounter significant cultural differences between, say, the Mediterranean world in Europe as opposed to the Northern European world. ${ }^{7}$ Within what one might have thought of as the largely culturally homogeneous European world, there are deep cultural divides - and it seems difficult to create a one-size-fits-all bioethics for this culturally diverse Europe. There is also great cultural diversity even within what might seem on the surface are culturally homogeneous areas within Europe and North America due to large immigrant populations from distant cultures and also due to cultural developments within native populations especially since the 1960's that have led to greater cultural diversity within population groups with similar cultural backgrounds. One might think here of the recent studies of the cultural distinctiveness of "millennials" in American culture or of the differences in attitudes toward basic ethical issues of different age cohorts in contemporary American culture.

These familiar and much-discussed motivations for concern with bioethics and culture have primarily to do with the relations of producers of bioethics to consumers. Cultural differences lead to difficulties of communication between those who claim to speak authoritatively about the difficult bioethical questions presented by contemporary biotechnology and the audience for these pronouncements. There is even talk about a new "imperialism" involving the efforts of formerly imperial powers in the North Atlantic World to impose there authority in bioethical matters on those who were formerly subordinate to them both politically and economically. ${ }^{8}$ This new "ethical imperialism" emerges as a result of the aspiration of contemporary bioethics to provide authoritative guidance in matters of action to all of those confronting modern bio-medicine and the ethical and social quandaries that it seems to bring in its wake.

(7) Note the lively recent discussions about whether there is a specifically "Mediterranean" bioethics (e.g., Mallia 2012) - and if there is how it is to be addressed. Interesting contributions to this discussion are found in Busquets et al. 2012; Carlioz et al. 2012; Kukoč 2012; and Leone 2012.

(8) The language of imperialism is used by many but discussions in Petersen (2011) are particularly significant. He says, "Increasingly, 'mainstream' bioethics concepts and principles have been applied globally to new sites and societies in what are arguably 'over-extended' and inappropriate ways." He goes on to say that one of the aims of his book "is to reveal the various manifestations and implications of bioethics' knowledge, as it has been applied within and across societies. In particular, I explore the dangerous implications of what might be described as 'bioethics imperialism'-a term that underscores the potentially damaging impacts of the extension of its rich Western, particularly US-focused approach to ever growing spheres of life." (Petersen 2011, 6; my emphasis) 
Bioethics is driven to seek universal scope for the norms of ethical practice it articulates and defends.

Cultural differences among the globalized audiences for bioethics make it difficult for bioethics to be what it both aspires to be - and sometimes claims to be - an authoritative voice standing outside the world of concrete cultural differences and providing moral guidance on the most fundamental choices confronting contemporary patients and health care workers. Bioethics seeks to speak authoritatively to everyone despite cultural differences. It seeks to rise above these differences (or perhaps to slip below them) to a lingua franca for guiding practical decisions in both treatment and research in contemporary biomedicine. It may be necessary to translate these authoritative and universal pronouncements into the "ethical dialects" of particular communities, but the translations are supposed to preserve the universal reach of the pronouncements. ${ }^{9}$

There is no doubt, I think, about the central focus on universality - the drive to speak to everybody - in bioethics even though this emphasis sometimes conflicts with another main emphasis in the contemporary rhetoric of bioethics - that on autonomy. While the reach for universality represents the aspiration of contemporary bioethics to speak to everyone despite cultural differences and cultural distance from the culture that produces the bioethics, the equally powerful emphasis on autonomy represents a quite different aspiration, the aspiration that everyone is allowed to speak for himself or herself. This simultaneous emphasis in contemporary mainstream bioethics on universality and autonomy is, of course, nothing new in ethics. It is just one more indication of the rootedness of contemporary western bioethics in the ethical traditions central to Western cultural life.

The ambition to give equal weight to these two notions and to place them at the heart of a conception of morality is found classically in its most developed form in the moral philosophy of Kant. ${ }^{10}$ Perhaps the most arresting image in Kant's moral philosophy is that of the "kingdom of ends," a set of social arrangements in which everyone is simultaneously a legislator and subject to legislation, simultaneously the source of the moral law and a creature bound to obey it. The quite different formulations of the Categorical Imperative and Kant's insistence in the Second Section

(9) I have addressed in Solomon 2006 these general difficulties under the heading of "export problems" for contemporary bioethics. Export problems are problems generally about how it is possible to export broadly western bioethical insights to cultures quite different from our own.

(10) Kant's central ethical works are The Groundwork of the Metaphysics of Morals (2012) and the Critique of Practical Reason (2002), both available in a number of different English translations and editions. Both works are committed to the compatibility of a strong commitment to universality and a strong commitment to Autonomy, though the focus on this compatibility is perhaps a bit stronger in The Groundwork. 
of his Groundwork that they are all "equivalent" represent his struggle to hold universality and autonomy together despite the obvious difficulties in doing so. ${ }^{11}$ One wants to say that if, as advocates of autonomy suggest, the requirements of morality are up to each of us in an important sense (every man his own moral philosopher, as it were) then why should we suppose that the legislative activity of each of us will converge, as advocates of universality must hold, on a single set of universal norms?

This struggle to hold these two notions together has been at the heart of the Kantian project from the seminal works of Kant himself down to the work of his most recent disciples in mainstream academic moral philosophy, John Rawls and his students. ${ }^{12}$ It is not surprising that the most prominent contemporary Kantians - Rawls, most notably - are also the premier philosophers of the modern liberal state, since it is only natural to think of the liberal state as the most significant attempt to combine universality and autonomy in a set of stable social arrangements - citizen sovereignty realized in a social setting dominated by authoritative universal legislation. ${ }^{13}$ Those moral philosophers most reluctant to accept Kant's commitment to the strong compatibility between universality and autonomy - Nietzsche, for example - are not surprisingly among the most aggressive critics of the modern liberal states and the more general liberal values embodied in it. ${ }^{14}$

The consumer side of the problem of bioethics and culture then is essentially the problem of how the aspirations of contemporary bioethics to provide a set of universal norms for guiding the most fundamental practical decisions of patients, researchers, and practitioners within contemporary biomedicine can be reconciled with the deep cultural differences among those whose actions the norms are designed to govern.

(11) It should not be surprising, I think, given the tension between these two notions that Kant's discussion of the different formulations of the Categorical Imperative and their "identity" provides occasion for some of the sharpest disagreements among Kant scholars on exactly what he meant by these claims. Like the vexed issues in understanding the traditional Christian doctrine of the Trinity, Kant's insistence simultaneously on the difference of the formulations and their identity can seem maddeningly difficult to fully grasp.

(12) The influence of Kant is most evident in the early chapters of Rawls' masterpiece, $A$ Theory of Justice (1972).

(13) Of course, there are important differences between Kant's use of the notion of autonomy in his view and its use in the work of contemporary liberals in political theory like Rawls. Kant's notion of autonomy was more metaphysically based and did not carry with it the same commitment to individualism one finds in contemporary liberals. It was also tied much more closely to a more traditional notion of rationality than Rawls's who is willing to make use of the much weaker notion of "the reasonable". Nevertheless, Rawls' work is a clear descendent of Kant's with regard to the notions of universality and autonomy.

(14) Perhaps Nietzsche's most trenchant criticism of liberal values is found throughout the Genealogy of Morals (2007). 
How can universal norms operate in a world of extreme cultural diversity - especially when that cultural diversity seems to be in the heart of the very communities in which we live? We no longer have to go abroad to encounter it.

Alan Petersen nicely sums up the central thought of the consumers' worry about bioethics and culture in his book, The Politics of Bioethics, when he says:

Bioethics is a product of a particular time (1960's and 1970's) and place, namely the US, and reveals the worldview and interests of relatively powerful, Western elite groups. It has evolved primarily from clinical and research contexts, and thus focuses on issues relevant to those contexts, for example, the clinician-patient relationship and the researcher-subject relationship, patient autonomy, confidentiality, informed choice, and so on. . . It is being applied globally to issues or problems confronting peoples that did not previously call for deliberation via bioethical frameworks and expertise."(Petersen 2011, 17-18)

\section{Producers' Questions}

There is another set of concerns in recent bioethics however, that has led to a particular focus on the relation of bioethics to culture. This set of concerns has not so much to do with the consumers of bioethics, as with its producers. In the relatively short history of bioethics, there has been great diversity among those producers of bioethics, with different academic disciplines taking turns as the primary voices in the development of the field of bioethics. There has been a great deal of interest in the history of the field in recent years and also in how that history seems to culminate in the past decade in a state of crisis. ${ }^{15}$ Alongside the recent histories of bioethics, there have also been a series of commentaries from a broadly social scientific perspective on the field that have raised fundamental questions about the theoretical approaches to bioethics and how they have failed to deliver the authoritative guidance that had been promised. ${ }^{16}$ Both this recent intense interest in the history of the field of bioethics and the attention paid to the area by social scientists reflects a more general self-consciousness on the part of those in the field about what the cultural role of bioethics ought to be-and how it has itself been shaped by the culture out of which it was born.

(15) Among the most important contributors to this history are Jonsen (2003), Brody (2009), Stevens (2000), and Evans (2012).

(16) By far the best of these social scientific commentaries is Fox \& Swazey 2008. 
One might say that contemporary bioethics is undergoing an identity crisis. In one respect, bioethics has been enormously successful as an academic field, experiencing enormous growth, especially in the North Atlantic world, since its founding in the tumultuous post-war years. The number of academic centers for the study of bioethics has exploded, as have the number of academic journals devoted to topics in bioethics and the number of graduate programs for training practitioners of bioethics. Virtually every college and university now has at least one course in bioethics (with no shortage of textbooks for those courses) and many have academic majors in the field. And almost all hospitals, biomedical research centers, or other health care facilities have an ethics committee which frequently employs someone described as a bioethicist — or at least draws on contemporary work in the field in carrying out its tasks. ${ }^{17}$

This second set of concerns, the "producers' concerns," is closely related to the consumer's concerns, but there are also significant differences. The consumers' concerns focus primarily on the question of how the authority of the general bioethical norms generated by, and putatively justified within, bioethics can be operative in the lives of agents from quite distant cultural backgrounds. How can, for example, bioethical norms generated in modern North Atlantic communities shaped by philosophical reflection and cultural history peculiar to this world get a grip on traditional Chinese patients who emerge from communities with quite different cultural histories and whose reflection on practical matters generally are shaped by quite different philosophical traditions, say, traditional Confucianism?

The producer's concern is expressed typically in a different question. How is it possible to generate by rational reflection from within the kind of diverse culture in which we live (a culture characterized by what John Rawls has called "reasonable pluralism") norms which can have universal authority? ${ }^{18}$ What philosophical techniques - if any — can be adequate to such a task? What methodology can prevent bioethical norms from being culture-bound? The consumer of bioethics asks, "How can I be bound by norms that come, in some sense, from outside my culture?" The producer of bioethics asks (or at least spectators skeptical of the ambitious claims of contemporary bioethics ask on behalf of the bioethicist), from what point of view can anyone speak to the contemporary issues in bioethics with the kind of reach and authority promised by, and expected of, contemporary bioethics? Both consumers and producers are concerned with the question of authority, but from quite different perspectives.

(17) Jonsen 2003 is particularly good at exploring the rapid growth in the influence and institutional presence of bioethics.

(18) "Reasonable pluralism" is defined explicitly in the lexicon in the introduction to Rawls' Political Liberalism (2005). 


\section{The Bush Gouncil and the Grisis in Bioethics}

The urgency of the producer's question about bioethics and culture has become evident in the last decade and a half as the result of a number of deep controversies in bioethics which have reached a level of incivility and breakdown of conversation seldom seen previously in bioethical discussions. There is no doubt that this breakdown in civility among bioethicists grew mainly out of the reaction of many "mainstream" or established bioethicists to the advent of the President's Bioethics Council in the Bush administration. The national bioethics bodies charged with advising government agencies on bioethical matters before the Bush administration had been dominated by established academic figures in bioethics. ${ }^{19}$ It was widely believed, however, that the constitution of the Bush Council radically departed from previous practices. And many established bioethicists took umbrage at that. Bush's selection of Leon Kass - a respected conservative public intellectual, a physician, and a scholar in the humanities, but not a mainstream bioethicist-and the membership of the Council that Kass chaired, signaled to many that the realm of bioethics had been politically compromised. The attacks on Kass and a number of other members of the Council were vitriolic and unrelenting. A number of mainstream bioethicists led this attack on the Council, including such widely respected figures as Art Caplan, Jonathan Moreno, and Ruth Macklin. Macklin's article (2006) in the Hastings Center Report, "The New Conservatives in Bioethics: Who are they and What do they Seek?" constituted one of the most powerful indictments of the Bush Council and those who put it together.

Macklin's attack on the committee claims that the members are a politically motivated cabal with neither the academic skills nor the appropriate motivations to serve in an advisory capacity on the vexed bioethical issues in contemporary culture. Her article opens with this apocalyptic pronouncement, "A new political movement has arisen in bioethics, self-consciously distinguished from the rest of the field and characterized by a new way of writing and arguing. Unfortunately, that new method is mean-spirited, mystical, and emotional. It claims insight into ultimate truth yet disavows reason." (Macklin 2006, 34) She develops her critique by criticizing the Council for, among other things, having too

(19) And there had been a large number of such bodies. These bodies were important not only because they added prestige to the emerging field of bioethics, but also because they provided a setting in which many of the leading philosophical and methodological ideas in bioethics were hammered out. Famously, it was while a student assistant on the council that advised congress and the president on methods for overseeing medical research that the young Tom Beauchamp hammered out the set of views that came to be the most influential theoretical orientation in bioethics - the view that came to be called principlism. 
many conservative journalists on it and not enough academically trained bioethicists; for being too close to the "most conservative wing" of the Republican party which she characterizes as "being obsessed with matters related to procreation, pre-natal life, and extracorporeal embryos" (Macklin 2006, 35); and for being generally anti-technology. She sums up her critique by exploring in some detail her claim that there are four characteristics of the writings of the "new conservatives" that sharply separate them from mainstream bioethicists: "metaphors and slogans as substitutes for empirical evidence and reasoned arguments; patently offensive analogies; deliberately misleading terminology; and an almost total absence of quotations from and citations to the people they are criticizing."(Macklin 2006, 38)

Macklin further developed her general critique of the Council in the context of an attack on their particular use of the notion of dignity in their deliberations. This attack, in a very brief article, "Dignity is a Useless Concept" (Macklin 2003), sparked an enormous literature and debate (sometimes referred to as the "dignity wars") that continues to rage within bioethics. In this article, Macklin defends three main claims. First, that "Dignity" adds nothing to what is "implied by the principles of medical ethics: respect for persons; the need to obtain voluntary, informed consent; the requirement to protect confidentiality; and the need to avoid discrimination and abusive practices." (Macklin 2003, 1419) Second that it is so vague as to function as "a mere slogan." (Macklin 2003, 1419-1420) And, third, that as a primarily religious notion, especially in Roman Catholic circles, it has no place in secular medical ethics. (Macklin 2003, 1420) Macklin proposes in short that bioethics can get along fine without the notion of "dignity" making do with the family of concepts associated with autonomy as they had been developed within mainstream bioethics in the decades before the intrusion of the politically (and possibly religiously) motivated Bush Council.

The Bush Council, taking note of Macklin's criticism, solicited and published a collection of articles by distinguished philosophers, theologians, and other scholars, four years later, Human Dignity and Bioethics (PCBE 2008). This volume attempted to explore and respond to her charge that the notion of dignity could be dropped from the list of terms of analysis in contemporary bioethics. The articles in this volume examined a number of ways that the notion of dignity might be useful in bioethical analysis. They also attempted to respond to Macklin's vagueness criticism, by exploring the roots of substantive notions of dignity in classical antiquity, Biblical religion, Kantian moral philosophy and $20^{\text {th }}$ century constitutions and international declarations.

If the member of the Council thought that this volume would quiet the criticism of their use of dignity in their deliberations, they were soon disabused of that thought. In a review of the book soon after it appeared, 
the distinguished Harvard neuro-scientist, Stephen Pinker, savaged the book and the Council. The review was entitled, provocatively enough, "The Stupidity of Dignity," (Pinker 2008) and it appeared not in a scholarly journal (as had Macklin's piece) but in The New Republic, a popular news journal read by a general intellectual audience. Like Macklin, Pinker raises some issue with the usefulness of "dignity" as a term of analysis in bioethics, claiming that it is too relative and fungible -and also too likely to be used in ways that will be harmful both to individuals and to the common good - to be allowed in as a primary term of analysis.

But Pinker saves his big guns for the motives of the Council in using the notion, which he claims they have attempted to place at the center of bioethical discussion. Of these motives he says that they "spring from a movement to impose a radical political agenda, fed by fervent religious impulses, onto American biomedicine." (Pinker 2008, 27) Further he accuses the Council of being anti-technology in that they claim that "even if a new technology would improve life and health and decrease suffering and waste, it might have to be rejected, or even outlawed, if it affronted human dignity." (Pinker 2008, 28) He further resorts to a number of attacks on the structure of the Council and to ad hominem attacks on the Council and its members. Of the structure he argues that there are too many Christians, especially Catholics, and too few social scientists as members of the Council. He goes on at great length about some of the personal eccentricities of the chairman, Leon Kass. And he develops in detail his claim that the Council's deliberations are part of a larger Catholic conspiracy, an attempt to do the Church's business by other means. He links this conspiracy to the popular Catholic journal First Things, and its very influential editor at the time, John Richard Neuhaus. He clinches his argument about the role of the Catholic Church in the deliberations of the Council by pointing out that there are more than 100 references to the notion of dignity in the Catechism of the Catholic Church!

One might say that Pinker's angry and badly argued screed is hardly worth taking seriously as a criticism of the Council, but it is worth noticing as a symptom of the deep unrest among commentators on bioethics in the last decade and a half. It would be a mistake, too, to suggest that the only persons who have made accusations of the politicization of bioethics are bioethicists on "the left" criticizing the Bush Council. Many bioethicists from all across the ideological spectrum have expressed similar worries.

Among those who expressed similar worries was Edmund Pellegrino, Kass's successor as head of the President's Council. Pellegrino a prominent Catholic physician-bioethicist who has been one of the most significant and moderate voices in bioethics from its beginning (but whom Pinkers would probably regard as part of the Catholic conspiracy in 
bioethics) has, like Pinkers, expressed worries about the loss of authority by bioethicists. He says in a recent piece reflecting on bioethics and politics that:

Bioethicists have become partisans, expert witnesses, media personalities, members of all sorts of commissions, identifying themselves or being identified as "red" or "blue" with the connotations these terms imply. Debates are becoming less civil, more adhominem and denunciatory. The threat of opposing parties or associations of bioethicists is already in the discussion state. The fragmentation of bioethics will surely drown out civil discourse and encourage partisan politics of the most malignant sort. The result is a growing rift between the bioethics community and the general public. Americans are addicted to the idea of technical expertise to which they turn for help in complex matters. As bioethicists air their conflicts, take to partisan politics, or drift from serious dialectics to polemics, the public is losing faith in their capacity to be helpful. (Pellegrino 2006, 576; my emphasis)

Both Pinkers and Pellegrino, though differing deeply no doubt on substantive matters in bioethics, share the view that the involvement of bioethicists in partisan debate, polemics and politics generally, damages the ability of bioethicists to speak with an appropriate authority in bioethical matters. They also seem to agree that the descent into partisanship and name-calling is a recent phenomenon - that there was an earlier time (perhaps not so long ago), a kind of bioethical golden age, when bioethicists were civil to one another and shared an approach which allowed them to work together without the rancor that exists between Pinker and Kass. More importantly perhaps, this golden age also allowed them to enjoy the respect of the audience for their bioethical advice, and to be able to speak authoritatively to that audience, to speak with a voice that their audience will accept as expressing, in Pellegrino's terms, "technical expertise."

\section{A Bioethical Golden Age?}

There is no doubt that many bioethicists believe that there was something like this golden age, and that the current incivility in the field and the harsh attacks and counter-attacks that characterize conversations in bioethics, are something new. It is also widely believed that what brought an end to the golden age was the excesses of the religious right (and their fellow-traveling conservative intellectuals) in pushing a political agenda that incorporated deep commitments on some central 
bioethical topics-especially topics having to do with reproduction, the status of the embryo, technological excesses, etc. ${ }^{20}$

On the other hand one might hold that the so-called golden age of bioethical discussion is as mythical as most golden ages are. In support of this view one might hold that the Bush Council did not create the deep disagreements in contemporary bioethics but merely allowed to come to the surface deep fissures within bioethics, and its normative foundations, that had been covered over in a number of ways since the creation of bioethics in the 1970's.

Many mainstream bioethicists have claimed that the Bush Council in some way took steps to disturb the settled state of bioethics that had governed the field and kept things amicable for the decades from the $70 \mathrm{~s}$ through the 90's - not exactly a golden age, perhaps, but close to it. Jonathan Moreno has famously coined the term, "the great bioethics compromise" as a label for a set of shared views among bioethicists that prevailed for the most part through the 1980' and 90's, and kept the peace in bioethics until the Bush administration allowed politics to intrude into the "clean, well-lighted place" of bioethics.

Moreno summarizes the Great Bioethics Compromise in the following formula: "Keep a close eye on scientific innovation for its societal implications, apply the brakes now and then as needed through regulations or guidelines or just the glare of public discussion, and let the bioethicists be the ones to analyze how all this is going." (Moreno 2010, 17) He further suggests that the goal of the Great Compromise was "to hold in balance two facts otherwise in tension: that there were from the beginning serious disagreements about the implications of certain technologies, especially in the area of reproduction, and that it was important to retain academic politeness within the small fraternity of bioethicists in the early years." (Moreno 2010, xviii)

There is no doubt that Moreno is right that from the 1970's through the 1990's there was a surface appearance of peace within bioethics, a peace that was broken in the years after the creation of the Bush Bioethics 
Council. ${ }^{21}$ During this period of peace the same bioethics experts appeared on the major national advisory boards, the same major textbooks were used in the majority of courses and dominated bioethics pedagogy, there was general agreement about which were the leading journals in the field, and, no doubt, canons of academic politeness were generally observed.

The question, though, is not whether there had been a period of surface peace within bioethics followed by a period of harshness and incivility. It seems obviously true that there had been a period when the authority of bioethicists was widely accepted, and that period had come to an end. The question is rather whether that period of peace represented a genuine consensus in reason about the fundamental principles of bioethics or whether it was rather a mere marriage of convenience between professional bioethicists of the time and those who were promoting the transformative biomedical technologies they were charged to assess. We may grant that the disputes surrounding the Bush Bioethics Council made the world of bioethical discussion more politically charged, while still wondering whether that was because it genuinely transformed that world, (disrupted a genuine consensus built on philosophical insight) or because it merely made clear what it had been all along? A powerful case can be made for the second alternative being the more adequate account. Evidence for this can be found I think in the history of bioethics and its

(21) There are surely a number of difficulties with Moreno's formulation of this compromise, however, worth noting. These difficulties give some indication as to why it did not hold. In an era when bioethicists were charged with giving "authoritative" advice on some of the deepest human issues concerning matters of life and death, pain and suffering, fundamental justice and injustice, the best the compromise could say is that "bioethicists be the ones to analyze how all this is going" and that the main motivation for this was the importance of retaining "academic politeness within the small fraternity of bioethicists." There is no hint in this formulation of the compromise as to why bioethicists should be the ones to "analyze how all of this is going." Why should they be given special authority in this area? What special expertise did they bring to the table? Why should they push aside scientists in these great discussions, when scientists had been at the heart of the most epistemically successful human institution in modern life - the modern natural sciences? And why should they be trusted as opposed to the various religious traditions (and their accompanying philosophical views) which had played such an important part historically in the fundamental discussions of ethical issues in medicine. These religious traditions had also hammered out and tested against human experience sets of principles, ends and virtues for governing the behavior of health givers and patients for centuries. In his discussion of the compromise he gives no hint of why bioethicists should be given the authority to analyze "How all of this is going."

But perhaps more importantly, one might ask why should we be so concerned with "academic politeness" among bioethicists. Given the depth of the disputes with which they were called on to deal, shouldn't we encourage the most vigorous debate and disagreement? And shouldn't we expect deep-sometimes seemingly incommensurable - disagreement on the issues taken up in this area? Of course, we should provide fora in which these vigorous debates can go on free of the threat of violence and coercion, but, while politeness is undoubtedly always important, it hardly seems required to be promoted as one of the two most significant features of the great bioethics compromise. 
relation to transformations in academic moral philosophy which helped give it birth. I turn to an examination of that history in the next section.

\section{Academic Moral Philosophy and the Birth of Bioethics}

Bioethics comes into existence in the United States in the 1960's and 1970 's. It is part of a more general movement in intellectual life to make fundamental thinking about ethics and morality of the sort that goes on in academic moral philosophy more relevant to the response to particular ethical issues as they arise for individuals and institutions. Bioethics, as a kind of applied ethics, comes into existence at roughly the same time as other areas of applied ethics-business ethics, feminist ethics, environmental ethics, etc. In being born, these various areas of applied ethics were responding to changes both in the culture of the period and in the moral philosophy of the period.

The most significant cultural changes involved the dramatic loss of influence of traditional centers of authority. The 1960s were a time of deep cultural dislocation in this country and Europe. ${ }^{22}$ Many formerly respected institutions lost their cultural authority, an energetic and market-driven youth culture thumbed its nose at its elders, the professions (e.g., law, medicine, and the clergy) lost power and authority within their institutional settings, and the family with its interlocking set of obligations and rights among parents and children was transformed almost beyond recognition. These aspects of the great social sea change of the 1960s add up to a kind of cultural revolution. The social dislocations associated with the civil rights movement, the Vietnam debate, the new technologies, the rise of individualistic approaches to human life, and the consequent pressure on traditional loci of moral authority led to significant changes in the way our culture deals with ethical issues. Instead of relying on traditional centers of ethical authority distributed across such diverse institutions as the family, the church, and the traditional professions, there was a turn to specialists in ethics and the academic settings in which such specialists made their homes. In particular, philosophers were called on to bring their expertise to bear on what was increasingly perceived as a crisis in our culture.

(22) The material in the next two paragraphs follows closely material from my article, "Filling the Void: Academic Ethics and Secular Medicine." (Solomon 2013) There are, of course, a number of different - and competing - accounts of the social dislocations of the 1960s. Among the most instructive, especially as concerns developments in academic ethics, are Fox and Swazey (2008), Stevens (2000), and Evans (2012). 
And nowhere was the crisis more pressing than in bioethics. ${ }^{23}$ The loss of cultural authority by traditional institutions occurred at the same time that revolutionary advances in biomedicine were raising ever more difficult questions for the culture. Who is entitled to have his or her life saved by a kidney machine if there are too few kidney machines to go around? Are we required to use all of the medical means at our disposal to save the lives of seriously disabled children? Is it sometimes permissible to shorten deliberately the lives of infants whose continued life promises nothing but pain and slow decline? How should we regulate the use of human subjects in medical experiments? And perhaps most controversially at the time, should women be afforded legal protection in the name of personal freedom for the act of killing their unborn children for any reason whatsoever? These questions were widely asked at the same moment that events such as the Harvard Ad Hoc Committee's redefinition of death became widely known, the scandals of the Tuskegee syphilis experiments were uncovered, and the Roe v. Wade abortion decision made the right to abortion universal and beyond legislative means of change. These fundamental moral questions, together with this series of earth-shaking events in biomedicine and our culture's inability to generate compelling and authoritative responses to them, provided much of the impetus for the revival of applied ethics in general and bioethics in particular.

But it was not only from changes in the culture that bioethics sprung. It, together with the other areas of applied ethics, were made possible by fundamental change in the orientation and methodology of moral philosophy at this same time. Academic moral philosophy in the Anglophone world had been largely dominated during the first half of the twentieth century by a conception of itself that left it no room to contribute to the public discussion of genuine concrete normative issues. The two dominant features of this self-conception were, first, a commitment to a sharp logical divide between facts and values - between, that is, factual claims about how the world is and normative or evaluative claims about how it ought to be-and, second, the methodological claim that moral philosophers should be restricted to semantic investigations of the meaning and logical implications of ethical claims and terms. This restriction of moral philosophy to "metaethics," taken in a narrow sense, also meant that moral philosophy was required to observe a strict neutrality with regard to substantive normative claims.

These two commitments of mid-twentieth century moral philosophy - we might call them "the fact-value thesis" and the "thesis of moral neutrality" - made it impossible for moral philosophy to have any

(23) An excellent account of the changes in bioethics is found in Jonsen 2003. 
significant influence on the responses to the substantial normative questions that pressed so hard during the period of the social dislocations of the 1960's. The fact-value thesis prohibited appeal to any actual factual matter as logically relevant to substantive normative questions, while the thesis of moral neutrality made it impossible for philosophical argument itself to either support or oppose substantive normative claims. ${ }^{24}$

Fortunately for the prospects for applied ethics, however, this methodological straight jacket on moral philosophy changed during the 1960 's and 70's. Both the thesis of moral neutrality and the fact-value thesis came under sustained attack in the 1950 's and 60 's ${ }^{25}$ and academic moral philosophy was allowed significantly more freedom to participate once again — as it had done traditionally — in the great normative debates within culture. The turning point came with the publication in 1972 of John Rawls' magisterial, A Theory of Justice. Building on much of the work of his predecessors in the 60's who had so powerfully undermined the restriction of moral philosophy to "metaethics," Rawls rejected both the crude formulations of the fact-value thesis and the thesis of moral neutrality and returned moral and political philosophy to its traditional task of providing foundational support to normative principles capable of supporting and criticizing the normative foundations of culture.

This return of academic moral philosophy to the normative arena constituted a genuine revolution in Anglophone academic moral philosophy and it had implications both for the academic disciplines involved (not only philosophy, but also moral theology, political theory, jurisprudence and those aspects of social science that are integrated with moral philosophy) and for the culture at large. ${ }^{26}$ The revolutionary nature of this change was widely celebrated and contributed in a number of different ways to the development in a very short time of the entire institutional structure of so-called "applied ethics" within the academy. Among the significant publications that celebrated the revolution was the young Peter Singer's remarkably prescient piece in the New York Times

(24) The best, and most mature, expression of moral philosophy committed to these two theses is the enormously influential work of R. M. Hare who presided over academic moral philosophy from his position as White's Professor of Moral Philosophy at Oxford from the 50's through the 70's. The best single expression of his views on these matters is found in Hare 1963.

(25) The most important expression of this criticism came from two extraordinary British philosophers, Elizabeth Anscombe and Philippa Foot. See especially Anscombe's very important piece, "Modern Moral Philosophy" (1958) and Foot's slightly later pieces, "Moral Beliefs" (1958b) and "Moral Arguments" (1958a).

(26) Once again, the material in the next two paragraphs follows closely from material in Solomon 2006. 
Magazine (1974) entitled, significantly enough, "Philosophers are Back on the Job., 27

Singer's piece was a celebration of what academic moral philosophy could be now that it was unleashed on normative questions. It is a victory call, joyfully announcing the end of a long period of irrelevance and stagnation of moral philosophy and moral philosophers. It explains how philosophy had broken free of an overly-rigid scientism and fixation on linguistic analysis in the first half of the twentieth century, and how, now that these pathologies are overcome, philosophy can venture into debates about morality and politics and take its proper place in policy discussions. Philosophy, credentialed by its appeal to reason, and its validation within the citadels of reason, modern universities, can finally provide the secure authority required to deal with the contemporary crisis in culture. It can also help us think through the ethical conundrums latent in rapidly advancing technologies. And, of course, he cites Rawls' A Theory of Justice as showing the way back to relevance on the part of moral philosophy.

Unfortunately, Singer's enthusiastic expectations for philosophy's authoritative role in dealing with deep cultural issues did not quite work out as he might have liked. Rawls had indeed revived the idea of classical normative theory and had developed a powerfully articulated version of a broadly Kantian traditional theory which was widely celebrated. Many early contributions to the new discipline of bioethics drew in powerful ways on Rawlsian theory, using it as a foundation for argumentative engagements with bioethical issues.

Rawls was only for a short period, however, the only moral philosopher with a well developed and defended foundational normative theory within the world of academic moral philosophy. Once Rawls had opened the door for moral philosophers to return to their traditional task of foundational normative thinking, many others slipped through behind him. And many of these developed normative theories which were as powerfully articulated as Rawls's-but were in deep conflict with his. Utilitarians like Derek Parfit and Shelly Kagan followed Sidgwick instead of Kant and developed consequentialist theories rooted in the thought of the $19^{\text {th }}$ century utilitarians. ${ }^{28}$ Still other philosophers, like Elizabeth

(27) At the time Singer wrote this piece he had only recently completed his Ph.D. under the direction of perhaps the fiercest opponent of the Rawlsian revolution, R. M. Hare, the White's Professor of Moral Philosophy at Oxford. Hare was, before Rawls replaced him, widely regarded as the most influential moral philosopher in the Anglophone world. Singer has gone on to become the most widely known practitioner of applied ethics, especially well known for his philosophical engagement in support of moral vegetarianism, infanticide, euthanasia, and stringent programs of global justice.

(28) See Parfit's very influential Reasons and Persons (1986), and Kagan's much later work, The Limits of Morality (1989). 
Anscombe and Alasdair MacIntyre, rejected both Kantian and consequentialist models for normative theories and returned to Aristotelian models for thinking about normative ethics. ${ }^{29}$ After Rawls, in fact, the world of normative ethical theories became a very complicated place. By rejecting the metaethical model of moral philosophy, Rawls opened the door for academic moral philosophy to participate in genuine normative thinking about fundamental cultural problems. But once this revolution took place the space of foundational normative thinking became densely populated by conflicting normative theories. From having too little normative theory in the first half of the twentieth century, we came to have, one might think, too much in the second half.

The turn to academic moral philosophy, to find an authoritative normative voice in dealing with the great normative questions of our time and to escape the conflicting and ill formulated demands of religious perspectives and the unreflective acquiescence in traditional views, as Singer clearly hoped to do, seems not to have paid off in the way he had hoped in the heady days of 1974 . The carefully formulated positions by secular moral philosophers in defense of particular sides in the great normative debates of our times seem only to have sharpened and deepened those debates. It is hardly too much to say that philosophers, in making clear the depths of the disagreements in the normative disputes within bioethics, moved our culture from the encounter with "mere" normative disagreements to the much more malignant culture wars that now beset us. Normative disagreement was exacerbated rather than made more manageable by the clear articulations of the competing foundational normative theories.

In commenting on this plurality of voices, Alasdair MacIntyre has argued that moral language is so disordered and fragmented today that when philosophers approach difficult ethical questions with their most sophisticated philosophical tools, they actually establish that the questions are not, after all, "merely" difficult to resolve, but rather impossible to resolve-at least in the terms in which we articulate them. ${ }^{30}$ The evidence provided by the entry of the competing voices of academic moral philosophy into many of these debates seems to suggest that he is right.

The significance of the contretemps over the Bush Bioethics Council looks quite different against the background of this account of the relation between the history of bioethics since its founding and developments in academic moral philosophy. The narrative shared by Moreno, Macklin, and Pinker (and countless other critics of the Bush Council) is that the

(29) For Anscombe see her revolutionary article, "Modern Moral Philosophy" (1958) and, for MacIntyre, his enormously influential book, After Virtue (1981).

(30) MacIntyre defends these claims in a number of different places, but perhaps most memorably in the opening chapters of After Virtue (1981). 
deep and increasingly uncivil divides within bioethics since the beginning of the Bush administration are the result of a political assault by the religious right (supported by a cadre of conservative intellectuals) on the peaceful village of mainstream bioethics. They claimed that right-wing ideologues politicized bioethics and tried to recruit its authority for partisan goals. The alternative picture sketched here is that these deep divisions are endemic to modern secular culture and have been laid bare by the development by academic moral philosophers of fully articulated foundational normative theories in the last four decades which bring fully to our consciousness the deep divides within the culture.

\section{Bioethical Half-Way Houses}

The implications for an account of the development of bioethics of this pluralism of deeply conflicting foundational normative theories in academic moral philosophy are complicated. It is also the case that these complications have not been as adequately explored as they should have been in the extensive recent literature on the history of bioethics. It is my suggestion, though I am unable to defend it as fully as is necessary here, ${ }^{31}$ that bioethicists have sought to invoke the authority of the secular, reason-based normative theories developed by academic moral philosophy over the past forty years in order to respond to the crisis in culture in the 1960's that provoked the creation of bioethics. Confronted, however, with the variety of these theories - and the deep conflicts among them - they have resorted to various strategies to try to avoid, or paper-over, these conflicts. They have attempted, that is, to find ways to enjoy the authority of foundational moral theory without making a commitment to one of the conflicting theories over another. Most of the models for bioethical thinking so much fought over throughout the history of bioethics have been designed to avoid taking sides in the deep normative disputes that lie at the heart of contemporary moral philosophy, while still giving some support from normative thinking for the ethical verdicts yielded by the method. We might think of such models of bioethical reasoning as ethical "half-way houses."

Certainly, the dominant normative model for bioethics since the 1980's, Beauchamp and Childress's principlism, is a model perfectly designed to give normative guidance in a world where there is deep and fundamental disagreement between the classical normative theories on

(31) I have discussed it further and provided more support for it in a number of other places. See especially Solomon 2006 and 2013. I hope to provide further support for it in a forthcoming General History of Anglophone Academic Ethics and its Engagement with Culture in the Twentieth Century which will place special emphasis on the applied ethics revolution in the 1970's. 
offer. ${ }^{32}$ The four principles in principlism offer comfort to consequentialists with the emphasis on beneficence and comfort to Kantians with the emphasis on non-maleficence and autonomy. By giving an account of the virtues which allegedly makes them at home in a theory dominated by rules and principles, Beauchamp and Childress even find some room in their theory for the deepest concerns of Aristotelians. Casuistical models, another popular half-way house, direct one's attention to particular cases in doing bioethical thinking, thus avoiding attention to the fundamental conflicting principles or rules in the competing normative theories that form the background for our ability to discern the differences among cases. The great variety of "common morality" approaches in bioethics, yet another form of half-way house, tend to focus on mid-level principles in normative ethics which, it is argued, are held in common among normative theories that fundamentally disagree in their foundational principles.

All of these "half-way" houses in bioethics seek to find a place where consensus can be reached on concrete normative issues without resolving the fundamental disagreements that divide contemporary neo-Kantians, consequentialists, New Natural Lawyers, neo-Aristotelians, and other varieties of foundational normative theories. This resort to "half-way houses" is a reflection in applied ethics of the more general assimilationist approach to normative theory, which has been becoming more popular in moral philosophy generally. Such assimilationist approaches to normative theory argue that the normative theories of the classical approaches-Aristotelian, Kantian, Consequentialist, and others-are largely compatible (or at least can be modified slightly to become compatible) in their implications for actual practice if interpreted charitably enough.

If it is true that bioethicists have sought consensus in bioethics by formulating methodological devices to avoid the genuine deep disagreements in which the best contemporary moral philosophy finds itself, then we might finally see the Bush Council dispute as simply a matter of a genuinely deep disagreement about fundamental matters in ethics. Steven Pinker and Leon Kass may simply disagree about fundamental issues in ethics. The sharpness of the attacks by Pinker and Macklin on the role of the concept of dignity in the Councils' work suggests the presence of a deep normative disagreement. What is at the

(32) Tom Beauchamp and James Childress wrote the first edition of their influential textbook, Principles of Biomedical Ethics, in the late 1970's (Beauchamp \& Childress 1979). In that volume they introduced their four principles for approaching issues in bioethics - autonomy, beneficence, non-malevolence, and justice. Their text is the best-selling textbook in the history of bioethics and the method for dealing with bioethical reflection they introduce there, principlism, is by far the most influential methodology of bioethical reasoning in the history of the field. 
bottom of the highly-charged conflict between them is not that one of them is guided by reason and the other by politics or religion, but that their ethical commitments are in the end in conflict. Kass and his supporters hold foundational normative views which place the notion of dignity in a central place while Pinker, Macklin, and the mainstream bioethicists who have been so critical of the Council hold foundational normative views which allow the autonomy family of concepts to displace the notion of dignity from the central place in which it is placed by Kass and his friends. ${ }^{33}$ How then should we think about this conflict if this is its true form? In the final section of this paper we will turn to two different proposals about how to respond to this fragmentation within bioethics.

\section{Two Responses to the Crisis}

This account above of the current state of bioethics brings into focus a view, widely held as we have seen in bioethics today, that there is a crisis of authority within the field. There is wide spread skepticism about the deliverances of bioethical experts and the committees on which they serve. Perhaps the greatest skepticism is that held by some bioethicists about other bioethicists. The name-calling episodes in the Bush Council disputes surely did great damage to the credibility and authority of mainstream bioethics. The critics of the Council accused the members of the Council of being politically driven and prey to emotional arguments and slogans instead of making use of careful and clear arguments in support of their positions. In making their attacks, however, the critics demonstrated that they, too, fell prey to these same weaknesses. What I called earlier in this paper an identity crisis in bioethics is the result of this general loss of confidence in the deliverances of bioethical "expertise." One further piece of evidence that such a crisis exists is the number of recent proposals to respond to it. In the final section of the paper I will briefly examine and evaluate two of the most significant recent proposals for responding to this crisis.

\section{John Evans' Response to the Grisis}

John Evans' recent book, The History and Future of Bioethics: A Sociological View (2012), is one of the most significant recent attempts to

(33) I have in mind here the kind of deep and incommensurable disagreements that MacIntyre (1981) explores in Ch. 2 of After Virtue. I am indebted at a number of places in this paper to MacIntyre's account of the fragmentation of the moral vocabulary in modernity and the implications of this fragmentation for the role of moral philosophy in providing normative guidance. Of course, he is in no way responsible for the use to which I put here some of his ideas. 
address the kind of crisis in bioethics, which we have identified in discussing the producer's concerns in bioethics and culture. He diagnoses the problem, provides an account of how it developed, and proposes a solution. As a sociologist himself who makes much of the fact that his academic work has been almost completely disengaged from the practice of bioethics, he claims a certain distance from the intramural disputes that have so dominated bioethical reflection in recent years. He says of himself that:

I have never conducted an ethical consult, served on an institutional review board, had or taught a class in bioethics, served on a government ethics commission, been a member of a bioethics center, or even made a strictly ethical contribution to a public debate about science and medicine.

(Evans 2012, xvi)

He has, nevertheless, been a close student of the history of bioethics since its creation a half-century ago, and brings to bear on the task of understanding this history-and the current state of bioethics-a sophisticated sociological perspective. He is especially well prepared to comment on the relation of bioethics and culture from the producer's perspective.

Evans' primary suggestion is that the current crisis in bioethics - what we have called a crisis in authority - is a jurisdictional crisis between competing professions to authoritatively pursue certain cultural tasks. The authority to carry out these tasks — or in Evans's terms "to have jurisdiction over them"-is granted by those who are the primary audience for the carrying out of the tasks. Patients are typically the jurisdiction granters with regard to the tasks of health care while ordinary citizens, who need to bequeath property, marry and divorce, or defend themselves against criminal charges in courts of law, are the jurisdiction-granters with regard to the tasks of the law. Evans is primarily concerned with competition for jurisdictions among professions where professions are always associated with systems of abstract knowledge, which are being evaluated by the jurisdiction-granters in the decision to grant jurisdiction in some particular area.

Evans brings this framework of concepts to bear on the particular jurisdictional crisis with regard to the profession of bioethics.

A key to understanding Evans' overall solution to the jurisdictional crisis within bioethics is his special definition of a bioethicist. He defines bioethicists as "professionals who use methods in a system of abstract knowledge wherein ethical recommendations are not based on their own personal values, or the values of a particular group in society, but based on the values of either the individuals involved with an ethical decision or the values of the entire public." (Evans 2012, xxi) According to this definition 
the defining characteristic of a bioethicist is that he or she makes recommendations with no particular attention paid to his or her own personal values. Evans admits that according to his definition all bioethicists are liberals and he goes on to say that "as liberals, their central concept is that they do not want to impose their values on others" (Evans 2012, xxi). He is also willing to bite the bullet on the fact that some groups that might be called "Christian bioethicists" (or Jewish or secular or Confucian bioethicists) are being improperly labeled according to his notion of a bioethicist. They are not bioethicists at all since they are basing their ethical recommendations on either their personal values or the values of their particular group. They should regard themselves, he says, as "philosophers, theologians, or some other title," but certainly not as bioethicists (Evans 2012, xxvi).

Evans argues that there are four task-spaces over which bioethicists have sought to have jurisdiction in the history of bioethics:

1) Health Care Ethics Consultation Jurisdiction - the tasks in this jurisdiction are the familiar ones associated with responding to questions of patients or their families with regard to value-laden concerns in patient treatment.

2) Research Bioethics Jurisdiction - the tasks in this space are again the familiar ones of serving on Internal Review Boards and overseeing the ethical concerns that arise with experimentation on human subjects.

3) Public Policy Bioethics Jurisdiction-Evans describes this task space as "Proposing ethical courses of action for scientists and physicians that can be incorporated into general policies that will be applied to all citizens." (Evans 2012, xxxi) The most common instance of this task would be serving on a government bioethics advisory board.

4) Cultural Bioethics Jurisdiction - according to Evans this task space consists of "trying to convince the ordinary citizens of the proper ethical course of action concerning a medical or scientific technology or practice." (Evans 2012, xxxiii)

Evans' assessment of the jurisdictional success of bioethics in these four areas is straightforward. With regard to the first two areas - health care consulting and research ethics - the jurisdiction of bioethicists is secure and without challengers according to Evans. The authority of bioethicists in ethics consults in a health care setting generally goes unchallenged, as does their authority in contexts of medical research oversight. With regard to the area of Cultural Bioethics, bioethicists lack jurisdiction there, but Evans say that they are nevertheless a strong contender. No particular profession has clear jurisdiction over this area. 
It is with regard to the third task space, the public policy task space, that there is a present crisis. The crisis is clearly exemplified according to Evans in the deep disputes between mainstream bioethicists and the members of the Bush Bioethics Council discussed in the previous section. He disagrees, however, with the account of this crisis defended by Moreno and the other mainstream bioethicists. While they argued that the crisis was precipitated by the politicization of bioethics by "conservative" bioethicists, Evans argues instead that the threat to the jurisdiction of mainstream bioethicists comes from a non-professional group altogether, social movement activists. ${ }^{34}$ Such activists have been able to gain a hearing in public policy task space because bioethics has delegitimized itself.

Evans argues that this delegitimization occurred because bioethicists tried to stretch their system of abstract knowledge too thin in order to have jurisdiction over cultural bioethics as well as the three other areas. Evans accepts that the system of abstract knowledge appropriate to bioethics as a profession is some version of principlism in which bioethics draws its value commitments from the common morality - the morality shared by those whom the public policies are intended to benefit. The delegitimization occurred because of what he calls a well know feature of professions. He quotes Abbott's study of the professions to this effect:

....as jurisdiction expands and as the ideas unifying it necessarily become more abstract, jurisdiction attenuates... A profession already widely spread will...lose strength in its current jurisdictions if it claims yet another one, forcing its justifying abstractions to the limits of vagueness." (Evans 2012, xxxv)

He concludes that in order for bioethics to retain its jurisdiction in public policy bioethics, it must cut back its ambitions for jurisdiction in cultural bioethics. As he says, "It is time to retrench around the profession's strengths." (Evans 2012, xxxv)

Evans' sophisticated sociological model for understanding questions of jurisdictions for bioethics is illuminating in a number of ways. Although many of the important details of his model aren't captured well in this brief summary, its basic ideas are relatively straightforward. Insofar as there is a crisis in authority in bioethics, he argues, it has only to

(34) Although Evans does not give a very precise account of what counts as "social movement activists," his examples make it clear enough what he has in mind. Among the groups would be the pro-life and pro-choice popular movements, advocates for the elderly like AARP, special advocacy groups for specific diseases or disabilities, and so forth. All of these groups have in common the pursuit of a certain "set of values" which are constitutive of their groups. 
do with the role of bioethics in public policy bioethics. On his view, bioethics never had an authoritative voice in cultural bioethics, so it can hardly be a crisis for the profession if it now fails to have one. The crisis in public policy bioethics, indeed, has arisen on his view largely because bioethicists have wanted to take jurisdiction over cultural bioethics as well as public policy bioethics. They have wanted to articulate and defend normative views in fundamental moral philosophy instead of restricting their attention to simply proposing public policy measures that fit with the measurable common morality of the community. In striving to achieve jurisdiction in cultural bioethics, they have stretched their system of abstract knowledge too far, thus endangering their jurisdiction in the public policy realm. The heart of Evans' argument here, leaving aside his technical language for a moment, is actually quite simple.

Bioethicists deploying their common morality-principlist methodology were secure in their public policy jurisdiction because their abstract system of knowledge fitted their role of adjudicating questions of public policy perfectly. They simply took careful steps to discern what the ethical orientation of the audience for the public policies was (i.e., the common morality) and, combining that knowledge with their more general (and morally neutral) skills in formulating clear and coherent policies, used it as a basis for making recommendations for appropriate public policy. Since the appropriate ethical orientation for guiding public policy is surely the ethical orientation of those who are to be governed by the public policy (at least this seems evident in a liberal democratic state), bioethicists seemed to have earned their jurisdictional role in the realm of public policy.

When bioethicists, however, tried to take their common morality-principlist methodology into the larger cultural debates that involved clashes with social movement activists (e.g., right to life groups, feminist bioethicists, advocates for particular disabilities, etc.) of various sorts, it was no longer obvious that their methodology was adequate. The recognition of its inadequacy in this arena, on Evans's view, led to its delegitimization as well in the public policy arena.

Evans' solution to resolving the crisis in bioethics with regard to public policy jurisdiction is also quite simple. It has two parts. First, he proposes that bioethicists should abandon any attempt to take jurisdiction over cultural bioethics. Indeed, even more powerfully, he proposes that they must remain silent altogether, qua bioethicists, in that area. Secondly, they must reform and refine the common morality principlism that represents the abstract system of knowledge of the bioethicist. He suggests a number of reforms, but by far the most important suggestion is that common morality principlism takes extra care to make sure that the common morality attributed to people is actually that morality that is common to them. To that end, he proposes that bioethicists enlist 
sociologists to do the careful survey work that will be necessary to discern exactly the elements of whichever morality is common - and to track changes in that morality. No longer will bioethicists be able to claim to discern the "common morality" by examining their intuitions and indulging in thought experiments in philosophy seminars. Sophisticated sociologically-vetted survey methods will be required if bioethicists are to regain their jurisdictional control of public policy bioethics.

Both Evans' diagnosis of the crisis in bioethics and his prescription for resolving that crisis deserve more attention than I can give them here at the end of this long paper. It is worth noting, however, that Evans' proposal (1) to sharply separate cultural bioethics from public policy bioethics and (2) to banish bioethicists from the realm of cultural bioethicists altogether is likely to leave many people unsatisfied. He is insistent throughout his treatment of these issues that we must keep the realm of public policy bioethics and cultural bioethics distinct, though he readily admits the difficulty in doing so. ${ }^{35}$

One wonders as well whether even if bioethicists could regain their credibility in public policy matters by following Evans's advice, and retreating completely from the great cultural debates they have so eagerly joined throughout their history, they might think that the price they would have to pay would be too great. If, as I suggested earlier in the paper, bioethics was called into existence by the cultural crisis of the 1960's and the need for an authoritative voice to provide guidance in dealing with the deep moral dilemmas thrown up by late modern culture, Evans's proposal is essentially to rule bioethicists ineligible for that conversation. They are removed from the game of fundamental moral debate. Bioethicists would regain their authoritative roles in public policy, on Evans' view, by refusing to engage the great cultural battles of the age and transforming themselves into handmaidens of political bodies. They would be assigned the special task of discerning with scientific accuracy the ethical sensibilities of the citizens under the care of those political bodies. Within this restricted area, they might regain their jurisdiction, but mightn't they think that in this case the cure is worse than the disease? They would

(35) He says, near the beginning of his book, "Obviously this cultural bioethics task space is difficult to demarcate in practice from public policy bioethics, in that many ethical claims implicitly or explicitly continue by saying that the government should create policy to support or oppose the use of some technology or practice. Moreover, government ethics commissions - a tool in the public policy task space- have often tried to act in both the public policy and cultural task spaces at once, speaking both to government officials and to the public. Yet, it is critical that we at least in principle try to detangle (sic) these two, because the lack of recognition of this boundary is one of the sources of the crisis for the bioethics profession. In a liberal democratic society these two jurisdictions have different jurisdiction-givers, and, critically, they will not and should not accept the same system of abstract knowledge." (Evans 2012, xxxiv) 
become, it seems clear, only the moral equivalent of sociologically sophisticated polling organizations.

\section{Progressive Bioethics}

It is ironic that another recent set of proposals for reforming bioethics to deal with its recent crisis, while seemingly in deep disagreement with Evans, ends up in something like the same place. A group of the politically left-wing critics of the Bush Council (led by Caplan and Moreno) have proposed in recent years a reformed bioethics which they call "progressive bioethics. ${ }^{36}$ It is not altogether clear what the precise features of this reformed bioethics might be, but there is no doubt that it would be an effort to simply absorb bioethics into a larger political movement. Inspired by pragmatism in philosophy and the progressive movement in early $20^{\text {th }}$ century American politics, progressive bioethics would also involve a retreat from any foundational role for philosophical argument in bioethics. Evans has been one of the sternest critics of progressive bioethics, declaring that:

Public Policy bioethics more broadly is also becoming more like dueling interest groups. For example, liberals have set up "progressive bioethics" associated with organs of the Democratic Party. While democratically legitimate, an interest group legitimation for the bioethics profession would lead to the end of public policy bioethics as we know it, and lead to two distinct public policy bioethics debates: a Democratic one and a Republican one, with the group out of power forming a sort of shadow debate. Obviously bioethics could no longer claim to not be representing a subgroup of the population. Developing this type of legitimacy is not a solution to the jurisdictional crisis; it will deepen the jurisdictional crisis. (Evans 2012, xxiv)

Evans is surely right that the move to overtly politicize bioethics would only exacerbate jurisdictional questions concerning public policy bioethics. It is unclear, however, that the turn to "progressive bioethics" is any more damaging to the original aspirations of bioethics than Evans's own gerrymandering of the field of bioethical discussion which leaves bioethics out of what is surely the most important-as well as the most intellectually engaging - aspects of contemporary bioethical inquiry.

(36) The founding documents for this movement are found in a book of essays, Progress in Bioethics: Science, Policy, and Politics (2010) edited by Jonathan Moreno and Sam Berger. 
It is ironic that both Evans and the advocates of progressive bioethics while trying to respond to the crisis of authority in bioethics end up removing bioethicists from any real position of authority. Evans bans the bioethicist altogether from the great foundational normative debates that seemed to call bioethics as a discipline into existence in the cultural crisis of the 1960's. The advocates of progressive bioethics on the other hand merely absorb the bioethicist into a larger political movement in which the bioethicist has no special authority in determining the values of that movement or in determining its particular responses to particular bioethical questions. In either case the bioethicist seems to give up the claim to authority that provoked the discussion in the first place.

There is currently no clear winner in the deep clash of views that focus on what I have called the "producers concerns about bioethics and culture." No one of the beautifully articulated and buttressed foundational normative theories developed by contemporary moral philosophers has been able to gain a clear advantage in reason over the others. Aristotelians, Kantians, consequentialists and natural lawyers continue to defend their opposing - and seemingly incommensurable - normative theories, with no clear signs of any one theory winning the day. Bioethicists continue to propose ways of dealing with the deep normative debates created by the cultural impact of the new technologies in biomedicine and the new cultural settings within which contemporary people live. It remains unclear, though, with what authority they put forward those views? I have suggested that the efforts of those like Evans and the "progressive bioethicists," as different as those proposals are in some respects, merely make the situation worse by cutting off (in quite different ways) the proposals of bioethics from any grounding in reasoned argument. It seems unlikely that these producers' concerns about the relation of bioethics and culture will be removed from the agenda of bioethics for some time.

\section{參考文獻}

Anscombe, Elizabeth. "Modern Moral Philosophy," Philosophy, 33 (1958), pp.1-16.

Beauchamp, Tom L., and Childress, James F. Principles of Biomedical Ethics (New York: Oxford University Press, 1979).

Briggle, Adam. A Rich Bioethics: Public Policy, Biotechnology, and the Kass

Council (Notre Dame: Notre Dame University Press, 2014).

Brody, Howard. The Future of Bioethics (Oxford: Oxford University Press, 2009). Busquets, Ester, Roman, Begona, and Terribas, Nuria. "Bioethics in Mediterranean Culture: The Spanish Experience," Medicine, Health Care, and Philosophy, 15:4 (Nov 2012), pp.437-451. 
Carlioz, Antoine, Wolyniak, Joseph G., and Le Coz, Pierre. "Is There Such a Thing as Latin Bioethics?" Medicine, Health Care, and Philosophy, 15:4 (Nov 2012), pp.461-467.

Engelhardt, Jr., H. Tristram, ed. Global Bioethics: The Collapse of Consensus (Salem: M \& M Scrivener Press, 2006).

Evans, John H. The History and Future of Bioethics: A Sociological View (Oxford: Oxford University Press, 2012).

Fan, Ruiping. "Confucian Reflective Equilibrium: Why Principlism is Misleading for Chinese Bioethical Decision-Making," Asian Bioethics Review, 4:1 (March 2012), pp.1, 4-13.

Foot, Philippa. "Moral Arguments," Mind, LXVII:268 (1958a), pp.502-513.

Foot, Philippa. "Moral Beliefs," Proceedings of the Aristotelian Society, 59 (1958b), pp.83-104.

Fox, Renee C., and Swazey, Judith P. Observing Bioethics (Oxford: Oxford University Press, 2008).

Hare, R. M. The Language of Morals (Oxford: Oxford University Press, 1951).

Hare, R. M. Freedom and Reason (Oxford: Oxford University Press, 1963).

Jonsen, Albert R. The Birth of Bioethics (New York: Oxford University Press, 2003).

Kagan, Shelly. The Limits of Morality (Oxford: Oxford University Press, 1989).

Kant, Immanuel. The Critique of Practical Reason, translated by Werner S. Pluhar ; introduction by Stephen Engstrom (Indianapolis: Hackett Pub. Co., 2002[1788]).

Kant, Immanuel. The Groundwork for the Metaphysics of Morals, translated and edited by Mary Gregor and Jens Timmermann; with an introduction by Christine M. Korsgaard (Cambridge: Cambridge University Press, 2012[1785]).

Kukoč, Mislav. "Development of Integrative Bioethics in the Mediterranean Area of South-East Europe," Medicine, Health Care and Philosophy, 15:4 (Nov 2012), pp.453-460.

Leone, Salvino. "The Features of a 'Mediterranean' Bioethics," Medicine, Health Care, and Philosophy, 15:4 (Nov 2012), pp.431-436.

MacIntyre, Alasdair. After Virtue (Notre Dame: University of Notre Dame Press, 1981).

Macklin, Ruth. "Dignity is a Useless Concept," British Medical Journal, 327:7429 (Dec 2003), pp.1419-1420.

Macklin, Ruth. "The New Conservatives in Bioethics: Who are they and What do they Seek?" Hastings Center Report, 36:1 (January-February 2006), pp.34-43.

Mallia, Pierre. "Is there a Mediterranean Bioethics?" Medicine, Health Care and Philosophy, 15:4 (Nov 2012), pp.419-429.

Moreno, Jonathan D. and Berger, Sam, eds. Progress in Bioethics: Science, Policy, and Politics (Cambridge: MIT Press, 2010).

Nietzsche, Friedrich. On the Genealogy of Morals, edited by Keith Ansell-Pearson; translated by Carol Diethe (Cambridge; New York: Cambridge University Press, 2007[1887]).

Parfit, Derek. Reasons and Persons (Oxford: Oxford University Press, 1986). 
Pellegrino, Edmund D. "Bioethics and Politics: 'Doing Ethics' in the Public Square," Journal of Medicine and Philosophy, 31:6 (2006), pp.569-584.

Petersen, Alan R. The Politics of Bioethics (New York: Routledge, 2011).

Pinker, Stephen. "The Stupidity of Dignity: Conservative Bioethics' Latest, Most Dangerous Ploy," The New Republic, 238:9 (28 May 2008), pp.28-31.

President's Council on Bioethics (PCBE). Human Dignity and Bioethics. (Washington, D.C.: President's Council on Bioethics, 2008).

Rawls, John. A Theory of Justice (Cambridge: Harvard University Press, 1972).

Rawls, John. Political Liberalism (New York: Columbia University Press, 2005). Singer, Peter. "Philosophers are Back on the Job," The New York Times Magazine, $17^{\text {th }}$ July 1974, pp.12-17.

Solomon, David. "Domestic Disarray and Imperial Ambition: Contemporary Applied Ethics and the Prospects for Global Bioethics," in Global Bioethics: The Collapse of Consensus, edited by H. Tristram Engelhardt, Jr. (Salem, MA: Scrivener Press, 2006), pp.335-361.

Solomon, David. "Filling the Void: Academic Ethics and Secular Medicine," in Ethics and the Challenge of Secularism: Russian and Western Perspectives, edited by David Bradshaw (Washington, D.C.: Council for Research in Values and Philosophy, 2013), pp.115-128.

Stevens, M. L. Tina. Bioethics in America: Origins and Cultural Politics (Baltimore: Johns Hopkins University Press, 2000).

Public Policy Advisory Network on Female Genital Surgeries in Africa. "Seven Things to Know about Female Genital Surgeries in Africa," Hastings Center Report, 42:6 (November-December 2012), pp.19-27. 